Pinyopusarerk, K. and C. E. Harwood (2003a): Surveys of seed orchards of key Australian tree species. Client Report No. 1242. CSIRO Forestry and Forest Products, Australia.

Pinyopusarerk, K. and C. E. HARWOOD (2003b): Flowering and seed production in tropical Eucalyptus seed orchards. In: TuRnBulL, J. W. (ed.). Eucalypts in Asia. ACIAR proceedings No. 111. Australian Centre for International Agricultural Research. Canberra. pp 247-248.

Shelbourne, C. J. A. (1992): Genetic gains from different kinds of breeding population and seed or plant production population. Sth. Afr. For. J. No. 160: 49-60.

SweEt, G. B. (1992): Seed Orchard Research and Management in the 1990s-A New Zealand Case study. In syntheses of IUFRO meeting on Mass Production for
Genetically Improved Fast Growing Forest Tree Species. AFOCEL, Paris, France, pp 110-118.

VArghese, M., D. Lindgren and A. Nicodemus (2004): Fertility and effective population size in seedling seed orchards of Casuarina equisetifolia and C. junghuhniana. Silvae Genet. 53: 141-192.

VARGhese, M., N. RAVI, S. G. Son and D. LindGren (2002): Variation in fertility and its impact on gene diversity in a seedling seed orchard of Eucalyptus tereticornis. In: WeI, R. P. and XU, D. (eds.). Eucalyptus plantationsResearch, Management and Development. World Scientific, Singapore. pp 111-126.

Venkatesh, C. S. and S. Kedharnath (1965): Genetic improvement of Eucalyptus in India. Silvae Genet. 14, 141-176.

\title{
Deterministic Simulation of Gains for Seedling and Cloned Main and Elite Breeding Populations of Pinus radiata and Implications for Strategy
}

\author{
By C. J. A. Shelbourne*), S. Kumar, R. D. Burdon, L. D. Gea and H. S. Dungey \\ Ensis Genetics, Private Bag 3020, Rotorua, New Zealand
}

(Received $11^{\text {th }}$ August 2006)

\begin{abstract}
Genetic gains in breast-height diameter were estimated using deterministic simulation. Simulations of gain from one generation of selection were undertaken in large Main and small Elite breeding populations for a range of heritabilities, with varying numbers of parents, families, seedlings/family, clones/family and ramets/ clone to aid revision of the New Zealand Pinus radiata breeding strategy.

Cloned versus seedling populations of equal numbers of plants were simulated, derived from open pollination, polycrossing, and pair crossing. Balanced within-family selection was used for 200, 400 and 800-parent Main breeding populations and among- and within-family selection for 25-parent Elite populations of 25 up to 100 full-sib families.

Predicted gains from within-family selection in the Main population were highest from cloned polycross families at all heritabilities and lowest for seedling fullsib families. Gains from cloned populations were higher than seedling equivalents at heritabilities $\leq 0.5$, and their advantage in gain was greatest at lower heritabilities. Elite populations of 25 parents showed similar trends but intensive among- and within-family selection resulted in much higher gains than from the Main,
\end{abstract}

*) Corresponding author: Email: cjashelbourne@hotmail.com. highest from the cloned options. The increase in gain with increased number of families diminished with more than 2-3 times as many families as parents.

A new strategy was proposed for $P$. radiata, based on the simulation results, involving an expanded Main breeding population of open-pollinated (OP) seedling families, together with pair-cross family seedlots already available, supported by parentage reconstruction using DNA markers. Forwards selection in small cloned Elite populations was proposed as the main source of seed orchard clones.

Key words: breeding populations, deterministic simulation, genetic gain, cloning, open-pollination, controlled pollination, backwards selection, forwards selection, seed orchard, Pinus radiata.

\section{Introduction}

When designing a breeding strategy for the genetic improvement of any species, one must have some means of predicting the amount of genetic improvement that will result from alternative strategies and population structures. Stochastic simulation is best for predicting gain over several generations, as well as predicting population means, size of additive variance, amount of inbreeding and effective population size or status number (LINDGREN et al., 1996), but requires making multi- 
ple runs for a specific scenario, each taking appreciable computer time. It is also possible to predict the genetic gain, population mean, etc., deterministically, from one or two cycles of selection, using derivatives of the wellknown relationship:

Gain $=$ selection intensity $\times$ phenotypic standard deviation $x$ heritability.

The advantage of deterministic simulation is that setting up a particular scenario is simple and calculation of results can be instantaneous, provided the necessary software is available. It appears best to use deterministic simulation to explore many scenarios and choose a few to simulate stochastically.

Deterministic simulation of selection and gain will help address a number of questions involving the management of breeding populations as Main and Elite populations. The role of backwards versus forwards selection, different mating designs for the Main and Elite populations, the numbers of parents, plants per family, and sites for testing, can all be studied. An important question is whether cloning of juvenile seedlings within families could be used to improve gains, reduce length of breeding cycle, and improve breeding efficiency.

This idea was first developed for tree breeding by W. J. Libby (LIBBY, 1964). Subsequently, cloning breeding populations for purposes of improving genetic information about forwards selections has been explored by many authors, e.g. NAMKOONG et al., 1966; SHELBOURne, 1969; Burdon and Shelbourne, 1971; Burdon and ShelBOURNe, 1974; MATHESON and LindGREN, 1985; BuRdON, 1986; Shelbourne et al., 1986; Shelbourne, 1992; DANELl, 1993; KARLSSON and Rosvall, 1993; RUSSELL and Loo-Denkins, 1993; GeA and Shelbourne, 1995; JEFFERSON and WEAVER, 1997; ROSVALL et al., 1998; Ruotsalainen and Lindgren, 2000; Danusevicius and LindGren, 2002; Rosvall and Mullin, 2003; SNEDDEN and VERRYN, 2004; IsIK et al., 2004.

There have been few reports of actual data from such cloned breeding populations, an exception being SNEDDEN and VERRYN (2004), where results from a cloned OP breeding population of Eucalyptus grandis were reported. However, cloned breeding populations are being applied on a wide scale in Norway spruce breeding in Sweden (KARLSSON and Rosvall, 1993; Rosvall et al., 1998). Cloning of seedlings of Pinus radiata has been used to establish clonal tests since 1968 (SHELBOURNE and Thulin, 1974), but the first clonal tests of cloned full-sib families of $P$. radiata, propagated from juvenile fascicle cuttings, were planted in 1986 (CONCHEYRO, 1998) and the first cloned Elite breeding populations in 1997 (S. KUMAR, pers. comm.). KUMAR (2006) found that genotypic values of clones in the 1986 trials correlated well with their breeding values, estimated from subsequent tests of their OP progenies.

NAMKOONG et al. (1966) presented a generalised equation for predicting gain, and derived equations for gain prediction from phenotypic, among-family and withinfamily selection for a variety of breeding-population and production-population scenarios. These were extended (Shelbourne, 1969; Shelbourne, 1992; GeA and ShelBOURNE, 1995) and later programmed by Verryn and
SNEDDEN (1998) as G-ASSIST, a user-friendly deterministic tool for genetic-gain prediction from a variety of scenarios, which was used in our study.

\section{Methods}

A key assumption for predicting gain from selection is that the trait is polygenically inherited. Under this condition, the size of the breeding population has fairly marginal effects on gain from a single trait, especially under balanced within-family selection.

It was further assumed that: the original parents are a random sample of the base population; pollination in an OP breeding population occurs randomly in the test area and the resulting families are perfect half-sibs; there is equal representation of pollen parents in polycrosses; pollen parents in polycross and OP breeding populations are equivalent; there is no truncation of additive genetic variance by selection; an additive genetic model is assumed, with no dominance and epistatic effects; pedigree reconstruction by DNA markers will avoid over-representation of pollen parents in selections from polycross and OP families; selection intensities are adjusted in G-ASSIST for finite family numbers and finite numbers of trees within families; selection is among-family and then within-family, not by combined index; selection-age and harvest-age traits are perfectly genetically correlated. G-ASSIST does not simulate multi-site testing, so genotype $\mathrm{x}$ site interaction variance must be assumed zero, but sufficient seedlings per family or ramets per clone were specified, so that testing on several sites would be feasible.

Predicted genetic gain is given by the generalised equation (NAMKOONG et al., 1966):

$$
\Delta \mathrm{G}=\mathrm{i} \sigma_{\mathrm{u}} \mathrm{b}
$$

Equation 1

where $\mathrm{i}=$ selection intensity; $\sigma_{\mathrm{u}}^{2}=$ phenotypic variance $=\sigma_{\mathrm{A}}^{2}+\sigma_{\mathrm{e}}^{2}$; where $\sigma_{\mathrm{e}}^{2}=$ environmental variance; $\sigma_{\mathrm{A}}^{2}=$ additive genetic variance; $\mathrm{b}=$ heritability of the particular selection system;

$\mathrm{b}=\mathrm{k} \sigma_{\mathrm{A}}^{2} / \sigma_{\mathrm{u}}^{2}$; where $\mathrm{k}=$ fraction of the total additive variance $\left(\sigma_{\mathrm{A}}^{2}\right)$ in the covariance of additive values for the particular relatives, e.g. $\mathrm{k}=1 / 4$ for selection among halfsib families; $\mathrm{k}=3 / 4$ for selection within half-sib families; $\mathrm{k}=1 / 2$ for selection among and within full-sib families. Phenotypic variance can include variance of half-sib family means, variance of full-sib family means, and variance of clone means within family.

In an OP breeding population/family trial some selection of pollen parents can be achieved by thinning the test on the basis of family mean and individual phenotype and/or clone mean, before collection of OP seed from selected individuals to establish the next OP breeding-population cycle. Therefore, the equation for predicting gain from forwards selection among and within open-pollinated families of a breeding population requires gain to be calculated separately for male and female parents. The female parents are selected on their family mean and on their phenotype within family. The male parents are selected through thinning, again on the basis of family mean, and on phenotype or of clone 
mean within family (see SHELbourne, 1992 and Appendix for equations for gain prediction).

\section{Simulation scenarios}

\section{Main breeding population}

Gains were simulated in a notional trait, diameter at breast height (DBH) at age 7 years, for balanced withinfamily selection in the Main breeding population. These scenarios are targeted at species like Pinus radiata, which are wind pollinated, grown in plantations, and easily propagated vegetatively from juvenile seedling material. In practice, the Main breeding population would be created by either collecting OP seed from selected parents in plantations or in earlier progeny tests, or by grafting selected parents into clonal archives and intermating them by pollen mix or pair-crossing. The Main populations simulated comprised 200, 400 and 800 parents and of the same number of OP, polycross, and pair-cross full-sib families (again the same number of parents as families). Family size throughout was fixed at 150 plants, as 150 seedlings, or 6 ramets $x$ 25 clones. For the OP option, among-family selection intensity for male and female parents was zero, and within-family selection ratio for female parents was one tree out of 150 seedlings in seedling BPs and one clone out of 25 from every family for cloned BPs, i.e., balanced within-family selection. For male-parent selection within seedling OP families, the best 30 seedlings or for cloned BPs, the best 5 clones per family were chosen at time of final assessment, and the remainder thinned out. Seed collection for establishing the next cycle must therefore be delayed by at least two years after thinning for $P$. radiata.

Gains were simulated for a polycross Main population, with zero among-family selection for both female and male parents, and within-family selection ratios for male and female parents of the best seedling out of 150 or the best clone per family out of 25 . For full-sib (double-pair-cross) families, the same selection ratios were applied as for the polycross population.

Gains from forwards-selected clonal seed orchards of the best 25 parents (best 25 families and best seedling or clone per family) were simulated for all Main breeding-population options. This strategy (of deriving orchard parents from the Main breeding population) would not usually be used if a suitable Elite breeding population was available. In addition, two backwardsselected clonal seed orchard options were simulated. The first was derived from forwards selection of the best individual in each of the best 100 families of the full-sib breeding population, followed by progeny testing via OP or polycrossed families, and reselection of the best 25 parents (Appendix Equation 10). The second was from "concurrent" backwards selection of the original parents of the OP breeding population (Appendix Equation 13) for the 200-parent population only.

Simulations were made with narrow-sense (individual-tree) heritabilities $\left(\mathrm{h}^{2}\right)$ of $0.1,0.2,0.3,0.4,0.5,0.6$ and 0.8. Additive genetic variance was kept constant
(560) and the environmental variance varied from 5040 for $\mathrm{h}^{2}=0.1$ to 140 for $\mathrm{h}^{2}=0.8$ to give the appropriate heritability, i.e., $\sigma_{\mathrm{e}}^{2}=\left(\sigma_{\mathrm{A}}^{2} / \mathrm{h}^{2}\right)-\sigma_{\mathrm{A}}^{2}$.

Breeding and production cycle lengths were assigned as follows:

OP breeding population: 1 year in nursery +8 years in field test (and thinning of test) +2 years till OP seed production $=11$ years.

Cloned OP breeding population $=11$ years +1 year for propagation $=12$ years.

Polycross and full-sib breeding populations: 1 year in nursery +8 years in field test +1 year for archive grafting +3 years for seed production $=13$ years.

Cloned polycross and full-sib populations: 13 years +1 year for propagation $=14$ years.

Forwards-selected orchard; 1 year in nursery +8 years in field test +7 years for orchard establishment and commercial seed production $=16$ years;

Backwards-selected orchard: 1 year in nursery +8 years in field test and OP seed collection +1 year in nursery +8 years field test +7 years for orchard establishment and commercial seed production $=25$ years.

\section{Elite populations}

In contrast to the Main breeding-population scenarios, the number of parents of the Elite populations simulated was set at 25 and the size of Elite populations was varied by the number of full-sib families created per parent. These varied from 25 (same number of families as parents or double-pair crossing), to 50, 75 and 100 (with 4 times as many parents as families). Family size was again fixed at 150 plants, as 150 seedlings or 10 ramets $\times 15$ clones, or 5 ramets $\times 30$ clones. The Elite was reconstituted with 25 parents, selecting no more than one tree per family. Population sizes therefore varied from 3,750 (25 families), 7,500 (50 families), 11,250 (75 families) and 15,000 plants (100 families) for the first series of scenarios. Gains from 10-clone seed orchards from forwards selection were simulated for all the seedling and cloned options, and a backwards-selected orchard was also simulated, as in the Main population, by selecting the best 10 families and the best clone per family.

Numbers of ramets per clone chosen for simulation were sufficient in practice for planting small numbers of ramets per site at multiple sites, with as many clones per family as possible to allow maximum selection intensities for clones within families. In practice, the main objective of across-site replication would be to allow selection for stable performance against $\mathrm{G} \times \mathrm{E}$ effects, rather than selection for single-site performance. If selection was for regional orchards, more ramets per clone per site would be needed. Five further scenarios were simulated for the Elite:

- full-sib family populations of 50 families of 250 plants, as 250 seedlings, and as 25 clones x 10 ramets per clone (12,500 plants);

- polycross populations of 25 families of 300 seedlings, and of 10 ramets $x 30$ clones $(7,500$ plants, making it the same size as the '50 families of 150 seedlings' option); 
- backwards-selection scenario, spanning two generations, utilising 50 open-pollinated families of 150 seedlings, followed by selection of the best seedling per family and then OP progeny testing of these 50 forwards selections to select 10 seed-orchard clones.

\section{Results and Discussion}

Some preliminary simulations of gain from selection within cloned families (not shown) allowed some insight into numbers of clones per family and ramets per clone needed for the later simulations. With a fixed number of 150 plants, gains were proved maximal at around 25 clones per family and 6 ramets per clone at $\mathrm{h}^{2} 0.2$, changing to 50 clones per family and 3 ramets per clone at $\mathrm{h}^{2}$ 0.4. Gains were also predicted for within-family selection in a cloned polycross population from increasing numbers of clones per family, with both 5 ramets and 10 ramets per clone (at $h^{2} 0.3$ ). For both ramet numbers, the curvilinear increase in gain plateaus at about 30 clones per family.

\section{Gains from Main breeding population}

Percentage gains from balanced within-family selection increase monotonically with increasing heritability for each of the six types of population (Table 1). Breeding-population gains are the same for population sizes of 200,400 and 800 parents because selection is only within family. For seedling-based populations, the OP popu- lation gains are mainly higher than the full-sib, but polycross population gains were always higher than for both OP and full-sib populations. The OP population relied primarily on selection of female parents (1:150), with a modest selection ratio of $30: 150$ or $20 \%$ for male parents through thinning of the trial area. The higher gain for the polycross and OP populations relative to the full-sib population is a function of the greater additive genetic variance available within half-sib versus full-sib families. Selection within OP and polycross half-sib families may involve some "unseen" and uncontrolled selection among potential full-sib families included within half-sib families, which will have a reducing effect on effective population size.

The cloned populations show higher gains than their seedling equivalents up to $\mathrm{h}^{2}=0.6$ (Table 1 ). The cloned polycross gave the best gains of all six scenarios up to $\mathrm{h}^{2}=0.5$, and above that the seedling polycross was best. The relative gains from cloned versus seedling populations depend partly on the total plants per family. With a fixed number of plants per family, larger family size allows more clones per family, and thus a higher selection intensity within family. The number of ramets per clone has been kept at 6 (equivalent to 2 ramets $x$ three sites), to allow many clones per family and thus a high selection intensity for a family size of 150 plants. The trade-off of selection intensity within cloned versus seedling families is an overarching reality of these fixedresource comparisons. The substantial benefits of for-

Table 1. - Predicted genetic gain (\%) in DBH from within-family selection in alternative types of breeding-population (applies alike to population sizes of 200, 400 and 800 families/parents).

\begin{tabular}{lccccccc}
\hline \multirow{2}{*}{$\begin{array}{c}\text { Breeding-population } \\
\text { type }\end{array}$} & \multicolumn{7}{c}{ Narrow-sense heritability } \\
\cline { 2 - 8 } & 0.1 & 0.2 & 0.3 & 0.4 & 0.5 & 0.6 & 0.8 \\
\hline Open-pollinated (OP) & 5.1 & 7.4 & 9.1 & 10.7 & 12.1 & 13.4 & 16.0 \\
Cloned OP & 8.6 & 10.8 & 12.1 & 12.9 & 13.5 & 13.9 & 14.5 \\
Polycross & 6.7 & 9.7 & 12.0 & 14.0 & 15.9 & 17.6 & 21.0 \\
Cloned polycross & 10.2 & 12.9 & 14.4 & 15.3 & 16.1 & 16.5 & 17.3 \\
Full-sib & 4.6 & 6.6 & 8.3 & 9.9 & 11.5 & 13.0 & 16.1 \\
Cloned full-sib & 7.3 & 9.5 & 10.9 & 11.8 & 12.6 & 13.1 & 13.9 \\
\hline
\end{tabular}

Table 2. - Predicted genetic gain (\% per year of breeding cycle) in DBH from withinfamily selection in alternative types of breeding population (applies to population sizes of 200,400 and 800 families/parents).

\begin{tabular}{lccccccc}
\hline \multirow{2}{*}{$\begin{array}{c}\text { Breeding-population } \\
\text { type }\end{array}$} & \multicolumn{7}{c}{ Narrow-sense heritability } \\
\cline { 2 - 7 } & 0.1 & 0.2 & 0.3 & 0.4 & 0.5 & 0.6 & 0.8 \\
\hline Open-pollinated (OP) & 0.46 & 0.66 & 0.83 & 0.97 & 1.10 & 1.22 & 1.45 \\
Cloned OP & 0.72 & 0.90 & 1.01 & 1.08 & 1.13 & 1.16 & 1.21 \\
Polycross & 0.51 & 0.74 & 0.92 & 1.07 & 1.22 & 1.36 & 1.61 \\
Cloned polycross & 0.73 & 0.92 & 1.03 & 1.10 & 1.15 & 1.18 & 1.23 \\
Full-sib & 0.35 & 0.50 & 0.64 & 0.76 & 0.88 & 0.99 & 1.24 \\
Cloned full-sib & 0.51 & 0.67 & 0.78 & 0.84 & 0.90 & 0.93 & 0.99 \\
\hline
\end{tabular}


wards selection across sites, a capability of cloned breeding populations (including selection of the male parents within an OP family by thinning on across-site clone performance), are not reflected in these simulations because $\mathrm{G} \times \mathrm{E}$ has not been modelled. Thinning the OP test before seed collection results in gain which depends on the effectiveness of within-family selective thinning of potential male parents. With cloned OP populations, selective thinning is based on clone means across all sites, and the relatively high heritability of clone means makes this highly effective.

Gains-per-year (Table 2) are strongly influenced by the different cycle lengths of OP- versus CP-, and seedling- versus cloned- comparisons, as defined above. Cycle lengths assumed are minimal for CP populations (polycross and full-sib) and could in practice be expected to be longer, favouring OP populations. Costs of seed will naturally be much lower for OP than CP seed. The highest gains per year are achieved by the cloned polycross at $h^{2} \leq 0.5$, though these are almost the same as those for the cloned OP population at the same heritabilities (because of its shorter cycle). At $h^{2}$ of 0.6 and greater the seedling polycross population gave highest gains per year. At all heritabilities, the polycross populations gave better gain per year than full-sib.

Effective population size (or status number) is well conserved with a full-sib breeding population under balanced within-family selection. Cloning of populations with fixed numbers of plants per family results in fewer genotypes per family, but balanced selection of one clone per family conserves effective population size. Maintaining effective population size under within-family selection in an OPBP and polycross BP would depend on developing marker-based methods of pedigree reconstruction to help avoid related selections, and under polycrossing, this would be simpler than in an OPBP (KUMAR et al., 2007; GEA et al., 2007).

\section{Gains from forwards-selected orchards derived from the Main}

Gains from forwards selection of 25 seed-orchard clones (Table 3, 200-parent population only shown) from
200-, 400- and 800-parent populations were greater with increasing population size but the resulting increase in gain is quite modest and far less than proportional to the increase in total numbers of plants, and in cost. For example, for a polycross population of seedlings, heritability 0.4, gain from a forwards-selected orchard is $22.6 \%$ for 200 families, $24.3 \%$ for 400 families and $25.8 \%$ for 800 families. Gains from such forwards-selected orchards were about double those from the breeding population. However, where a suitable Elite population was available, forwards selection of clones therefrom would result in higher gains than selection from the Main (see below).

Gains per year of production cycle (Table 4, 200parent population only shown) would be about $0.1 \%$ higher than for the 200-parent population for 400-, and $0.2 \%$ higher for the 800-parent population. Gains per year from forwards-selected orchards derived from cloned populations are greater than from seedlings, up to $\mathrm{h}^{2}=0.5$ and there is very little difference in gain or gain per year among orchards from cloned OP, polycrossand full-sib Main populations or amongst their seedling equivalents (production-cycle lengths are the same). Cloning of the various populations increases the gain component from within-family selection.

Gains from forwards-selected seed orchards derived from the various cloned populations are similar for all heritabilities. Strong family selection for the orchard utilises half the additive variance available among fullsib families (versus one-quarter available among halfsib families) and this has helped give roughly equal gains from the orchards from the full-sib BP to those from polycross- and OP-BPs, though these would need pedigree reconstruction to avoid selecting orchard clones from different half-sib families that have the same pollen parent.

Gains from a backwards-selected orchard of 25 clones derived from a full-sib breeding population, followed by OP progeny testing, are about one and half times those from a forwards-selected orchard from the cloned full-sib breeding population (Table 3), but gains per year are all lower than for forwards-selected orchards (Table 4).

Table 3. - Predicted genetic gain (\%) from forwards- and backwards-selected clonal orchards of 25 clones from alternative types of breeding population. Population size 200 families and 200 parents.

\begin{tabular}{|c|c|c|c|c|c|c|c|c|}
\hline \multirow{2}{*}{$\begin{array}{l}\text { Orchard type } \\
\text { (selection } \\
\text { mode) }\end{array}$} & \multirow{2}{*}{$\begin{array}{l}\text { Breeding- } \\
\text { population type }\end{array}$} & \multicolumn{7}{|c|}{ Narrow-sense heritability } \\
\hline & & 0.1 & 0.2 & 0.3 & 0.4 & 0.5 & 0.6 & 0.8 \\
\hline \multirow[t]{6}{*}{ Forwards } & OP & 14.5 & 17.9 & 20.4 & 22.6 & 24.5 & 26.4 & 29.8 \\
\hline & Cloned OP & 17.9 & 21.1 & 22.7 & 23.8 & 24.6 & 25.1 & 25.9 \\
\hline & Polycross & 14.5 & 17.9 & 20.4 & 22.6 & 24.5 & 26.4 & 29.8 \\
\hline & Cloned polycross & 17.9 & 21.1 & 22.7 & 23.8 & 24.6 & 25.1 & 25.9 \\
\hline & Full-sib & 16.2 & 18.6 & 20.5 & 22.2 & 23.7 & 25.3 & 28.6 \\
\hline & Cloned full-sib & 18.8 & 21.5 & 23.0 & 24.1 & 24.8 & 25.4 & 26.3 \\
\hline Backwards & Full-sib (25: 100) & 27.5 & 30.6 & 32.7 & 34.5 & 36.1 & 37.8 & 41.1 \\
\hline $\begin{array}{l}\text { Concurrent } \\
\text { backwards }\end{array}$ & $\begin{array}{l}\text { Original parents of } \\
\operatorname{OPBP}(25: 200)\end{array}$ & 15.5 & 16.4 & 16.8 & 16.9 & 17.0 & 17.1 & 17.2 \\
\hline
\end{tabular}


Table 4. - Predicted genetic gain (\% per year of breeding cycle) from forwards- and backwards-selected clonal orchards from alternative types of breeding population. Population size 200 families and 200 parents.

\begin{tabular}{|c|c|c|c|c|c|c|c|c|}
\hline \multirow{2}{*}{$\begin{array}{l}\text { Orchard type } \\
\text { (selection } \\
\text { mode) }\end{array}$} & \multirow{2}{*}{$\begin{array}{l}\text { Breeding- } \\
\text { population type }\end{array}$} & \multicolumn{7}{|c|}{ Narrow-sense heritability } \\
\hline & & 0.1 & 0.2 & 0.3 & 0.4 & 0.5 & 0.6 & 0.8 \\
\hline \multirow[t]{6}{*}{ Forwards } & OP & 0.91 & 1.12 & 1.28 & 1.41 & 1.53 & 1.65 & 1.86 \\
\hline & Cloned OP & 1.12 & 1.32 & 1.42 & 1.49 & 1.54 & 1.57 & 1.62 \\
\hline & Polycross & 0.91 & 1.12 & 1.28 & 1.41 & 1.53 & 1.65 & 1.86 \\
\hline & Cloned polycross & 1.12 & 1.32 & 1.42 & 1.49 & 1.54 & 1.57 & 1.62 \\
\hline & Full-sib & 1.01 & 1.16 & 1.28 & 1.39 & 1.48 & 1.58 & 1.79 \\
\hline & Cloned full-sib & 1.18 & 1.34 & 1.44 & 1.51 & 1.55 & 1.59 & 1.64 \\
\hline Backwards & Full-sib (25: 100) & 1.10 & 1.22 & 1.31 & 1.38 & 1.45 & 1.51 & 1.64 \\
\hline $\begin{array}{l}\text { Concurrent } \\
\text { backwards. }\end{array}$ & $\begin{array}{l}\text { Original parents of } \\
\text { OPBP }(25: 200)\end{array}$ & 0.97 & 1.03 & 1.05 & 1.06 & 1.06 & 1.07 & 1.08 \\
\hline
\end{tabular}

Gains per year from "concurrent" backwards selection are also substantially lower than from forwards-selected OP and full-sib BPs (except at $\mathrm{h}^{2}=0.1$ ). Surprisingly, such gains increase rather little with increasing heritability.

\section{Gains from Elite populations}

Gains from seedling and cloned Elite populations of 25 parents showed increased gains with increasing number of families. The marginal gain, however, diminished substantially with 75 families or more (Table 5). Gains from

Table 5. - Predicted gain (\%) from Elite breeding populations of 25 parents and 25, 50, 75 and 100 families, seedling versus cloned (selection of 25 clones or 25 seedlings as new parents), with varying combinations of clones/family (c) and ramets/clone (r).

\begin{tabular}{|c|c|c|c|c|c|c|c|c|c|}
\hline \multirow[t]{2}{*}{ Family size } & \multirow{2}{*}{$\begin{array}{l}\text { Elite population } \\
\text { (cloned or seedling) }\end{array}$} & \multirow{2}{*}{$\begin{array}{l}\text { No. of } \\
\text { families }\end{array}$} & \multicolumn{7}{|c|}{ Narrow-sense heritability } \\
\hline & & & 0.1 & 0.2 & 0.3 & 0.4 & 0.5 & 0.6 & 0.8 \\
\hline \multirow{12}{*}{$\begin{array}{l}\text { Seedling versus } \\
\text { cloned, } 150 \\
\text { plants/family }\end{array}$} & $\begin{array}{l}\text { Seedling (150 } \\
\text { trees/family) }\end{array}$ & 25 & 4.3 & 6.3 & 7.9 & 9.5 & 10.9 & 12.4 & 15.4 \\
\hline & & 50 & 9.7 & 11.8 & 13.5 & 15.0 & 16.5 & 18.0 & 21.0 \\
\hline & & 75 & 11.6 & 13.8 & 15.5 & 17.1 & 18.6 & 20.1 & 23.1 \\
\hline & & 100 & 12.9 & 15.1 & 16.8 & 18.3 & 19.9 & 21.3 & 24.4 \\
\hline & Cloned (15c, 10r) & 25 & 7.2 & 9.0 & 9.9 & 10.6 & 11.0 & 11.3 & 11.8 \\
\hline & & 50 & 12.4 & 14.3 & 15.3 & 16.0 & 16.4 & 16.8 & 17.2 \\
\hline & & 75 & 14.3 & 16.3 & 17.3 & 18.0 & 18.5 & 18.8 & 19.2 \\
\hline & & 100 & 15.5 & 17.5 & 18.6 & 19.2 & 19.7 & 20.0 & 20.5 \\
\hline & Cloned $(30 c, 5 r)$ & 25 & 6.7 & 9.0 & 10.4 & 11.4 & 12.2 & 12.8 & 13.8 \\
\hline & & 50 & 12.0 & 14.4 & 15.8 & 16.9 & 17.7 & 18.4 & 19.3 \\
\hline & & 75 & 13.9 & 16.4 & 17.9 & 19.0 & 19.8 & 20.4 & 21.4 \\
\hline & & 100 & 15.1 & 17.6 & 19.1 & 20.2 & 21.0 & 21.7 & 22.6 \\
\hline \multirow{2}{*}{$\begin{array}{l}\text { Seedling/cloned } \\
250 \text { plants/fam. }\end{array}$} & Seedling (250/fam.) & 50 & 10.1 & 12.3 & 14.1 & 15.7 & 17.3 & 18.8 & 22.1 \\
\hline & Cloned $(25 \mathrm{c}, 10 \mathrm{r})$ & 50 & 13.6 & 15.8 & 16.9 & $17 . .6$ & 18.1 & 18.5 & 19.0 \\
\hline \multirow{2}{*}{$\begin{array}{l}\text { Polycross: } \\
\text { seedling/cloned } \\
300 \text { plants/fam. }\end{array}$} & Seedling (300/fam.) & 25 & 7.0 & 10.0 & 12.4 & 14.6 & 16.5 & 18.4 & 21.9 \\
\hline & Cloned (30c, 10r) & 25 & 11.9 & 14.3 & 15.4 & 16.1 & 16.6 & 16.9 & 17.4 \\
\hline
\end{tabular}


cloning these families with 15 clones per family and 10 ramets per clone were higher than for the corresponding seedling populations, up to $\mathrm{h}^{2}=0.4$. With 30 clones per family and 5 ramets per clone, the gain from the cloned populations was higher than the seedlings' up to $\mathrm{h}^{2}=$ 0.5 . Gains were slightly higher for the 30 -clone $\times 5$ ramet options than the 15 -clone $\times 10$ ramet options at heritabilities above 0.2 .

For the second family-size option of 250 plants per family with 50 families, representing $66 \%$ more plants (Table 5), the seedling BP gains were only very slightly larger than for such seedling populations with 150 plants per family, but cloning with 25 clones per family resulted in appreciably higher gains than from the equivalent 50-family cloned option with 15 clones per family. Greater advantages with clones are generally realised at the highest numbers of plants per family, thus allowing larger numbers of clones per family, higher selection intensity and higher gain. At these numbers of plants per family, increasing the numbers of seedlings per family do not give commensurate increases in selection intensity and gain.

A seedling polycross Elite population of 25 (half-sib) families and 300 plants per family at $\mathrm{h}^{2} \leq 0.5$ gave lower gains than the equivalent-sized 50-full-sib-family seedling population, because of more effective amongfamily selection in full-sib populations. However, cloning the polycross families gave almost identical gains to the cloned full-sib population with 50 families (same population size) because within-family selection gave higher gain than from seedlings. Polycrossing could thus be used, in conjunction with pedigree reconstruction, to simplify the mating for cloned Elites where pair-crossing was difficult or impossible.

\section{Gains from forwards-selected orchards from Elites}

Gains from forwards-selected 10-clone seed orchards, simulated for each seedling and cloned Elite option (Table 6) are higher than from the 25 clones selected as breeding-population parents, but not greatly so. Gains from orchards derived from cloned populations with 30 clones/family and 5 ramets/clone are a little higher than from 15 clones/family and 10 ramets/clone. Cloned populations gave somewhat superior orchard gains to seedling populations at $\mathrm{h}^{2} \leq 0.5-0.6$. Their real advantages would be realised more fully where $\mathrm{G} \times \mathrm{E}$ was appreciable and numbers of plants were not fixed. The orchard from the cloned polycross did as well or better than the orchard from the equivalent-sized cloned 50family options. Increasing total plants per family from 150 to 250 gave little additional orchard gain from the seedling families but more orchard gains than from the smaller cloned 50-family populations.

Simulations of gains from a backwards-selected 10clone orchard, derived from the 50-family seedling population by progeny-testing 50 forwards selections, gave gains that were over one-third greater than from the orchards from cloned 50-family populations. However, these orchards would be planted at least nine years later than those from the cloned forwards selections, if OP testing was used for backwards selection.

Table 6. - Predicted gain from 10-clone seed orchards from seedling versus cloned Elite breeding populations of 25 parents and 25, 50, 75 and 100 families.

\begin{tabular}{|c|c|c|c|c|c|c|c|c|c|}
\hline \multirow[t]{2}{*}{ Family size } & \multirow{2}{*}{$\begin{array}{l}\text { Elite population } \\
\text { (cloned or } \\
\text { seedling) }\end{array}$} & \multirow{2}{*}{$\begin{array}{l}\text { No. of } \\
\text { families }\end{array}$} & \multicolumn{7}{|c|}{ Narrow-sense heritability } \\
\hline & & & 0.1 & 0.2 & 0.3 & 0.4 & 0.5 & 0.6 & 0.8 \\
\hline \multirow{12}{*}{$\begin{array}{l}\text { Seedling versus } \\
\text { cloned, } 150 \\
\text { plants per family) }\end{array}$} & \multirow{4}{*}{$\begin{array}{l}\text { Seedling ( } 150 \\
\text { seedlings/family) }\end{array}$} & 25 & 10.7 & 12.9 & 14.6 & 16.2 & 17.6 & 19.1 & 22.2 \\
\hline & & 50 & 13.6 & 15.9 & 17.7 & 19.2 & 20.7 & 22.2 & 25.3 \\
\hline & & 75 & 15.1 & 17.4 & 19.2 & 20.8 & 22.3 & 23.8 & 26.9 \\
\hline & & 100 & 16.1 & 18.4 & 20.2 & 21.8 & 23.3 & 24.8 & 27.9 \\
\hline & \multirow[t]{4}{*}{ Cloned $(15 \mathrm{c}, 10 \mathrm{r})$} & 25 & 13.6 & 15.6 & 16.7 & 17.4 & 17.9 & 18.2 & 18.7 \\
\hline & & 50 & 16.5 & 18.6 & 19.7 & 20.4 & 20.9 & 21.2 & 21.7 \\
\hline & & 75 & 17.9 & 20.1 & 21.2 & 21.9 & 22.4 & 22.7 & 23.2 \\
\hline & & 100 & 18.9 & 21.0 & 22.2 & 22.9 & 23.3 & 23.7 & 24.2 \\
\hline & \multirow[t]{4}{*}{ Cloned $(30 \mathrm{c}, 5 \mathrm{r})$} & 25 & 13.1 & 15.5 & 17.1 & 18.2 & 19.0 & 19.6 & 20.6 \\
\hline & & 50 & 16.0 & 18.6 & 20.1 & 21.2 & 22.0 & 22.7 & 23.7 \\
\hline & & 75 & 17.5 & 20.0 & 21.6 & 22.7 & 23.6 & 24.2 & 25.2 \\
\hline & & 100 & 18.4 & 21.0 & 22.6 & 23.7 & 24.5 & 25.2 & 26.2 \\
\hline \multirow{2}{*}{$\begin{array}{l}\text { Seedling/cloned } \\
250 \text { plants/fam. }\end{array}$} & Seedling (250/fam.) & 50 & 14.1 & 16.4 & 18.2 & 19.9 & 21.5 & 23.1 & 26.4 \\
\hline & Cloned (25c, 10r) & 50 & 17.8 & 20.0 & 21.2 & 22.0 & 22.5 & 22.9 & 23.4 \\
\hline \multirow{2}{*}{$\begin{array}{l}\text { Polycross } \\
\text { seedling/cloned } \\
300 \text { plants/fam. }\end{array}$} & Seedling (300/fam.) & 25 & 11.5 & 14.7 & 17.1 & 19.3 & 21.3 & 23.1 & 26.6 \\
\hline & Cloned (30c, 10r) & 25 & 16.4 & 18.9 & 20.2 & 20.9 & 21.4 & 21.7 & 22.2 \\
\hline $\begin{array}{l}\text { Backwards } \\
\text { selected orchard } \\
\text { from } 50 \text { seedling } \\
\text { full-sib families }\end{array}$ & $\begin{array}{l}\text { Seedling ( } 150 \\
\text { trees/family (and } \\
\text { backwards- } \\
\text { selected orchard) }\end{array}$ & 50 & 22.3 & 25.1 & 27.1 & 28.8 & 30.4 & 31.9 & 35.1 \\
\hline
\end{tabular}


Gains per year of cycle were not calculated for Elite breeding populations as all options are based on CP families, full-sib or polycross, seedling populations requiring at least $1+8+1+3=13$ years, with $\mathrm{CP}$ done on grafts of forwards selections. Cloned options would require an extra year for propagation, possibly more if more cloned trial sites were planted. If the cloned families are also planted and managed as a breeding archive at one good seed-producing site, CP could be undertaken there immediately after selection of parent clones for the next cycle of breeding (based on across-site clone means) which would reduce the cycle to about 12 years. Some clones will be selected from which orchards can be rapidly propagated by grafting.

Conversion of a cloned Elite test area into a seed orchard by heavy thinning on clonal breeding values would provide an immediate source of commercial OP or $\mathrm{CP}$ seed with relatively high gain. If the two sublines of the Elite had become inbred, provided clones from each subline are planted in intimate mixture, a high level of outcrossing could occur.

\section{Precision of clonal selection}

As shown in stochastic simulations by BURDON and KUMAR (2004), gains from forwards selection exceeded those from backwards selection on a population basis. The precision of forwards selection of seedlings within families depends on the narrow-sense heritability $\left(h^{2}\right)$ applicable to within-family (phenotypic) selection, which will often be low, depending on the trait. Clonal replication of each seedling raises this heritability and thus the precision of clone-in-family selection. For instance, with $\mathrm{h}^{2}$ of 0.2 , typical of several traits in $P$. radiata, with 10 ramets per clone, the corresponding $\mathrm{h}^{2}$ of clone means is 0.71 . Individual-tree $\mathrm{h}^{2}$ within seedling families and of heritability of clone means within families will both be lower than equivalent narrow-sense and clone-mean heritabilities, depending on family type.

\section{Departures from the assumptions for deterministic simulation}

The main assumption for these simulations of polygenic inheritance of most traits appears valid enough for $P$. radiata breeding, an important possible exception being selecting for resistance to a new disease (BURDON and GEA, 2006). Among the other assumptions listed under "Methods", the parents will not be a random sample of the base population; in an OP breeding population test area pollen is likely to come from both inside and outside the test, as such a test can seldom be established without risk of pollen inflow from neighbouring stands. Pollen contamination may or may not reduce gains and effective population size. The equivalence of pollen-parent composition of $\mathrm{OP}$ and polycross mating is also uncertain. There is very little information about the representation of male parents in pollen-mix pollination, especially with numerous pollens in the mix.

The assumption of a purely additive genetic model is appropriate for most traits in radiata pine except early growth rate. Genotype x environment interaction $(\mathrm{G} \times \mathrm{E})$ is likely to be appreciable rather than zero, thus the benefits in gain from cloning may be larger than indicat- ed. The assumption that pedigree reconstruction will be feasible seems appropriate, and already successes in this area are being recorded. The use of among- then within-family selection, rather than combined selection, is unlikely to seriously bias gain comparisons from different scenarios. The assumption of perfect genetic correlation of selection- and harvest-age traits will generally inflate gains, but should not affect comparisons of different strategies.

\section{Proposed New Zealand breeding and orchard strategy}

A revised breeding strategy for $P$. radiata in New Zealand must be a continuation of the existing breeding programme and so a combined strategy for Main and Elite populations is proposed below which builds on existing material, is near-optimal in gain and gain per year, and should be 'doable' in a short time frame. It should also be sustainable over several generations with minimum increase in inbreeding.

A combined OP and pair-crossed seedling Main breeding population would include about 500 parents and would be advanced by balanced within-family selection. Selections for the Main from 1993-planted pair-cross families have been tested as open-pollinated families and these would be incorporated in the new Main population, itself made up predominantly of OP offspring of numerous forwards selections, particularly those from the 885-, 887- and 888-series OP tests, now almost 20 years old. This will properly utilise this unique material, offspring of nearly 1000 selections from the last-available, pre-seed orchard stands originating from large numbers of non-intensively-selected seed parents, plus offspring of 300 selections from native American populations. OP seed would be collected from all selections not grafted in archives. Archived selections would be mated as double pair-cross families. Adding about $400 \mathrm{OP}$ families from parents unrelated to advanced-generation material will substantially broaden the genetic base of the new breeding population and greatly raise its status number.

One or more new full-sib Elite populations, of 24 parents and 48 families each, would be cloned by about 20 clones per family, and would form pre-production populations from which forwards-selected clones would be chosen for orchards, eventually replacing current backwards-selected orchards. The Main population would be divided into at least two sublines which would accommodate new, unrelated parents. Each Elite population would be divided (as at present) into two sublines of 12 parents. The Main breeding population would be enriched each generation from the unpedigreed plantings of the 13 natural subpopulations of radiata pine, planted in 1980-82, which should themselves each soon be recycled by bulked OP seed from an average of about 50 parents per sub-population (G. T. STovold, R. D. Burdon and L. D. GEA, unpubl.).

Simulations of the proposed strategy were done to compare gains and predicted mean $\mathrm{DBH}$ of Main and Elite populations after one generation. The Main population was simulated with 400 parents, 400 OP families, 
90 seedlings per family (which would in practice be planted at three sites, total plants 36,000 ), and was recycled by balanced within-family (forwards) selection. Gains from open-pollinated clonal orchards of 10 forwards selections and from 10 concurrent backwardsselected clones, derived from the parents of the Main population, were also simulated.

A special-purpose cloned Elite population was simulated comprising 24 parents, initially selected from the Main by backwards selection, with 48 full-sib families (24 parents versus 25 were used to enable splitting the population into two sublines). This Elite was cloned by 20 clones/family, 12 ramets/clone (in practice, two ramets/clone/site, and planted at six sites, total plants 11,520). From the cloned Elite population simulated forwards selection was made of 10 clones/elite breed, for a CP seed orchard.

\section{Predicted gains from OP Main breeding population}

The predicted gains from the 400-parent OP Main (Table 7) were similar to those from the OP seedling option of the first simulations (Table 1), and for the forwards-selected orchard are about $2 \%$ higher at all heritabilities than for the forwards-selected orchard simulated from a 200-parent population (Table 3) (because of the higher selection intensity possible among families). Predicted mean $\mathrm{DBH}$ of the next generation of the breeding population, for instance for $\mathrm{a} \mathrm{h}^{2}$ of 0.2 , was $238 \mathrm{~mm}$ versus the predicted mean $\mathrm{DBH}$ from the forwards-selected seed orchard of $267 \mathrm{~mm}$, and from the backwards-selected orchard of $272 \mathrm{~mm}$. For heritabilities of 0.3 and higher, the forwards-selected orchard gains are a little higher than from (concurrent) backwards selection

\section{Predicted gains from cloned full-sib Elite breeding popu- lation}

Conservatively, this cloned Elite population of 24 parents and 48 families was initiated from the means (for different heritabilities) of the best 50 backwards-selected parents of the Main, with 20 clones/family and 12 ramets/clone. Gains of the cloned Elite population (Table 8 ) were very similar to those predicted for the 50-family cloned Elite of the first simulations (Table 5) which had 15 clones/family and 10 ramets/clone. At $\mathrm{h}^{2} 0.2$, the predicted Elite mean DBH was $293 \mathrm{~mm}$ versus $238 \mathrm{~mm}$ for the Main.

The predicted gains from a 10-clone orchard, forwards-selected from the 48 families and 960 clones of the Elite at no more than one clone per family (Table 8), at all heritabilities were only about $4 \%$ higher than for the Elite breeding population. For $\mathrm{h}^{2}$ of 0.2 , the predicted mean orchard DBH was $303 \mathrm{~mm}$ versus $293 \mathrm{~mm}$ for the Elite breeding population.

These gains could be increased somewhat with more families per parent in the Elite and thus more intensive family selection, and by more clones/family and more ramets/clone. Turning over the generation sooner and repeating the selection process, will increase gain per year.

The great advantage of the cloned Elite population in this context is that it will rapidly deliver forwardsselected clones for seed production which have been selected across six sites in the face of $\mathrm{G} \times \mathrm{E}$. If the cloned Elites were planted sufficiently widely and sufficient ramets per clone were used in each site, regionallyadapted orchard clones could be selected for regions or particular forest owners. Further important advantages of cloning the Elite populations, with their specialised breeding objectives, is that destructive evaluations of clones can be made without loss of genotypes or disruption of the trial. Management of an archive of all the Elite clones, established at or somewhat after the cloned elite trials, could facilitate and accelerate generation turnover and increase breeding efficiency. Thinning cloned Elite trials on clone means and conversion to seed orchard/seed stands is also feasible.

\section{Concluding remarks}

An OP seedling Main population was proposed in the light of the experiences in $P$. radiata breeding of the

Table 7. - Predicted gain (\%) and predicted mean DBH $(\mathrm{mm})$ from within-family selection in OP Main breeding population (90 seedlings per family), with gains and means from forwards-selected orchard, and backwards-selected orchard from previous generation's parents.

\begin{tabular}{ccccccc}
\hline Heritability & $\begin{array}{c}\text { Breeding population } \\
\text { (within-family } \\
\text { selection) }\end{array}$ & \multicolumn{5}{c}{ Seed orchard } \\
\cline { 3 - 7 } & Gain \% & $\begin{array}{c}\text { Mean } \\
\text { DBH }\end{array}$ & Gain \% & $\begin{array}{c}\text { Mean } \\
\text { DBH }\end{array}$ & Gain \% & $\begin{array}{c}\text { Mean } \\
\text { DBH }\end{array}$ \\
\hline 0.1 & 4.9 & 233 & 16.6 & 259 & 20.6 & 268 \\
0.2 & 7.0 & 238 & 20.3 & 267 & 22.5 & 272 \\
0.3 & 8.7 & 241 & 22.8 & 273 & 23.2 & 273 \\
0.4 & 10.2 & 245 & 24.9 & 277 & 23.6 & 274 \\
0.5 & 11.5 & 248 & 26.8 & 282 & 23.8 & 275 \\
0.6 & 12.8 & 250 & 28.6 & 285 & 24.0 & 275 \\
0.8 & 15.2 & 256 & 31.8 & 293 & 24.2 & 276 \\
\hline
\end{tabular}


Table 8. - Gains (\%) and parental and predicted improved mean DBH for cloned Elite breeding population ( 24 parents, 48 full-sib families, 20 clones per family, 2 ramets/ clone, at 6 sites) and resulting forwards-selected seed orchard of 10 clones.

\begin{tabular}{cccccccc}
\hline Heritability & $\begin{array}{c}\text { Parental } \\
\text { mean } \\
(\mathrm{mm})\end{array}$ & \multicolumn{3}{c}{ Cloned Elite breeding population } & \multicolumn{3}{c}{ Forwards-selected orchard } \\
\cline { 3 - 8 } & & $\begin{array}{c}\text { Gain \% } \\
\text { per cycle }\end{array}$ & $\begin{array}{c}\text { Gain \% } \\
\text { per year }\end{array}$ & $\begin{array}{c}\text { Improved } \\
\text { mean } \\
(\mathrm{mm})\end{array}$ & Gain\% & $\begin{array}{c}\text { Gain\% } \\
\text { per year }\end{array}$ & $\begin{array}{c}\text { Improved } \\
\text { mean } \\
(\mathrm{mm})\end{array}$ \\
\hline 0.1 & 254 & 12.6 & 0.83 & 286 & 16.2 & 1.08 & 295 \\
0.2 & 257 & 14.1 & 0.94 & 293 & 17.9 & 1.19 & 303 \\
0.3 & 258 & 14.9 & 1.00 & 297 & 18.7 & 1.25 & 306 \\
0.4 & 259 & 15.4 & 1.03 & 299 & 19.3 & 1.28 & 309 \\
0.5 & 259 & 15.8 & 1.05 & 300 & 19.6 & 1.31 & 310 \\
0.6 & 260 & 16.0 & 1.07 & 302 & 19.9 & 1.32 & 312 \\
0.8 & 260 & 16.4 & 1.09 & 303 & 20.2 & 1.35 & 313 \\
\hline
\end{tabular}

past, as well as the results of the gain simulations. OP seed collection from forwards-selected individuals has proved much quicker and cheaper for turning over a generation of the Main breeding population than collection of scion material, grafting and establishment of clonal archives for controlled pollination. Executing large CP programmes in the past has invariably proved slow and costly. Half-sib OP progenies also provide good estimates of parental breeding values, which may be utilised for introducing parents with new selection traits from the Main to new Elites or new seed orchards. In addition, gains from OP Main breeding populations, thinned selectively before seed collection and managed by balanced within-family selection, have in these simulations been equal or better than from full-sib populations. The risks of selecting half-sib related individuals from different OP families are real, but may be managed by spreading that risk over a large Main population and by using molecular markers to determine male parentage. These tools should be better developed and cheaper to use in future.

A seedling- rather than a cloned Main population was favoured in this instance because of cost, complexity, and the relatively new large-scale application of the technology of cloning seedlings. There are also advantages in maintaining many genotypes within each OP seedling family deriving from a large number of male parents, as this provides more suitable material for intensive selection for genes of low frequency and large effect that might be important for resistance to new diseases (BURDON and GEA, 2006). Unreplicated block plantings of seedling OP families of the Main would also allow greater selection intensities within families.

A balanced within-family selection strategy in the Main has been adopted to minimise reduction in genetic variance, build-up of inbreeding and loss in status number, and would provide long-term sustainability to the strategy in the light of the severe reduction of status number experienced in the past. Undoubtedly there will be some among-family selection in this and early generations of the Main, but this will be balanced by recruitment from the gene resources and was not simulated.
The OP Main population is also well suited to quickly incorporating the offspring of the very best selections from the native-population gene resources. These gene resources themselves need to be managed by open pollination to maintain a wide genetic base, with as little contamination as possible from narrowly-based seed orchard-derived pollen parents (G. T. STovold, R. D. Burdon and L. D. GEA, unpubl.).

The Elite population structure chosen is essentially that proposed by JAYAWICKRAMA and CARSON (2000), and has not been further explored in terms of number of parents, set at 24. Simulations by other authors assuming the polygene model, recently reviewed (e.g. Rosvall et al., 1998) confirm that this is close to an optimal number for high gain, without too-rapid build-up of inbreeding.

Apart from the superior gains obtained from clonewithin-family and among-family selection as simulated, the principal benefits of cloning this population will be to make clonally-tested forwards selections quickly available for use in orchards. These selections will have been selected for stability against $\mathrm{G} \times \mathrm{E}$, which is a most important benefit of cloning. Establishment of an archive of the 960 clones of the Elite a little later than the time of establishment of the cloned tests, and its management for accelerated breeding and seed production will be also be crucial in accelerating generation turn over and production of commercial seed of the breed.

The most important change in strategy for the New Zealand radiata pine breeding programme that could result if these proposals are implemented, would be the increased breeding efficiency from discarding repetitive backwards selection, with its gross extension of the breeding cycle, in favour of forwards selection in a cloned Elite for choosing parents for seed orchards. The other major improvement will be in dramatically expanding the effective population size of the Main and making it sustainable by balanced within-family selection. 
The role of a cloned Elite population for producing tested clones for clonal forestry deployment has not been addressed here. If the clones of an Elite could be stored and maintained in a juvenile state (or better still rejuvenated), they could form an economic source of candidate clones, which could be tested on further sites and in large monoclonal plots by companies marketing clonal planting stock. Further simulations of the Elite breeding-population/clonal-deployment interface are needed.

\section{Acknowledgments}

The deterministic simulations were all done using GASSIST, supplied by CSIR Water, Environment and Forestry Technology, Pretoria, South Africa, and we are grateful to STEVE VERRYN for help in solving some initial problems with its application. The advice of TOBY STOVOLD and MARK MiLLER about practical aspects of the NZ breeding programme is gratefully acknowledged. The financial support for this study by the Radiata Pine Breeding Consortium is also gratefully acknowledged.

\section{References}

Burdon, R. D. and L. D. GEA (2006): Pursuit of genetic gain and biotic risk management for Pinus radiata in New Zealand. pp. 133-140. In: 'Breeding for Success: Diversity in Action', edited by C. F. MERCER. Proc. $13^{\text {th }}$ Australasian Plant Breeding Conference, Christchurch, New Zealand 18-21 April 2006.. www.apbc.org.nz.

BURDON, R. D. (1986): Clonal forestry and breeding strategies - a perspective. pp. 645-659 in Proc. IUFRO Working Parties on Breeding Theory, Progeny Testing and Seed Orchards. Williamsburg, Va., USA. October 13 1986.

Burdon, R. D. and C. J. A. Shelbourne (1971): Breeding populations for recurrent selection: Conflicts and possible solutions. NZ J. For. Sci. 1: 174-193.

Burdon, R. D. and C. J. A. Shelbourne (1974): The use of vegetative propagules for obtaining genetic information. NZ J. For. Sci. 4: 418-425.

BuRDON, R. D. and S. KumAR (2004): Forwards versus backwards selection: trade-offs between expected genetic gain and risk avoidance. NZ J. For. Sci. 34: 3-21.

DANELL, O. (1993): Tree breeding strategy: are we too concerned conservationists but inefficient breeders? In: Proc. Nordic Group for Tree Breeding. Edinburgh, Scotland, 6-10 October 1993, edited by S. J. LEE.

DANUSEVICIUS, D. and D. LINDGREN (2002): Efficiency of selection based on phenotype, clone and progeny testing in long-term breeding. Silvae Genet. 51(1): 19-26.

ConcheYRo, S. C. (1998): Evaluation of the 1986-1987 radiata pine clonal trials at Forest Research, New Zealand. M. Sc thesis, Massey University, Palmerston North, New Zealand.

GeA, L. D. and C. J. A. Shelbourne (1995): Gain expectations from control-pollinated main and elite breeding populations and corresponding production populations. p. 876 in Proc. CRCTHF-IUFRO Conference. Eucalypt Plantations: Improving Fibre Yield and Quality, Hobart, Australia, edited by B. M. PotTs et al.

GeA, L. D., R. M. MCConnochie and S. S. Wynyard (2007): Parental reconstruction for breeding, deployment and seed-orchard management of Eucalyptus nitens. NZ J. For. Sci. 37: 23-36.

JAYAWICKRAMA, K. J. S. and M. J. CARSON (2000): A breeding strategy for the New Zealand Radiata Pine Breeding Cooperative. Silvae Genet. 49: 82-90.
IsIK, F., B. Li and B. GoldFarb (2004): Clonal progeny testing and selection in forest tree improvement programs. p. 111 in Proc. 2004 Joint Conference of Division 2 "Forest Genetics and Tree Breeding in the Age of Genomics: Progress and Future", edited by B. LI and S. McKeand. November 1-4, 2004, Charleston, SC, USA.

JEFFERSON, P. A. and S. WeAVER (1997): Gains from clonal testing in the breeding population, pp. 226-230 in "IUFRO'97 Genetics of Radiata Pine" Proc. NZFRIIUFRO Conference. 1-4 December and Workshop 5 December, Rotorua, New Zealand, edited by R. D. BuRDON and J. M. MOORE, FRI Bulletin No. 203.

Karlson, B. and O. Rosvall (1993): Breeding programmes in Sweden-Norway spruce. In: Proc. Nordic Group for Tree Breeding, Edinburgh, Scotland, 6-10 October, 1993. Edited by S. J. LEE.

KumaR, S. (2006): Correlation between clonal means and open-pollinated offspring performance, and its implications for radiata pine breeding strategy. Can. J. For. Res. 36: 1968-1975.

Kumar, S., S. Gerber, T. E. Richardson and L. GEA (2007): Testing for unequal paternal contributions using nuclear and chloroplast SSR markers in polycross families of radiata pine. Tree Genetics \& Genomes 3: 207-214.

LIBBY, W. J. (1964): Clonal selection and an alternative seed orchard scheme. Silvae Genet. 13: 32-40.

LINDGREN, D., L. D. GEA and P. A. JEFFERSON (1996): Effective number and coancestry in breeding populations following within family selection. Silvae Genet. 45: 52-59.

Matheson, A. C. and D. LindGRen (1985): Gain from the clonal and the clonal seed orchard options compared for tree breeding programs. Theor. Appl. Genet. 71: 242-249.

NAmkoong, G., E. B. SNyder and R. W. STONECyPheR (1966): Heritability and gain concepts for evaluating breeding systems such as seedling orchards. Silvae Genet. 15: 76-84.

Rosvall, O., D. Lindgren and T. J. Mullen (1998): Sustainability, robustness and efficiency of a multi-generation breeding strategy based on within-family clonal selection. Silvae Genet. 47: 307-321.

Rosvall, O. and T. J. Mullin (2003): Positive assortative mating with selection restriction on group coancestry enhances gains, while conserving genetic diversity in long-term forest tree breeding. Theor. Appl. Genet. 107: 629-642.

RuOTSAlAinen, S. and D. LiNDGREN (2000): Stratified sublining: a new option for structuring breeding populations. Can. J. For. Res. 30: 596-604.

Russell, J. H. and J. A. Loo-Dinkins (1993): Distribution of testing effort in clonal genetic tests. Silvae Genet. 42: 98-104.

Shelbourne, C. J. A. (1969): Tree breeding methods. New Zealand Forest Service, Forest Research Institute, Technical paper No. 55 .

Shelbourne, C. J. A. and I. J. Thulin (1974): Early results from a clonal selection and testing programme with radiata pine. NZ. J. For. Sci. 4: 387-98.

Shelbourne, C. J. A., R. D. Burdon, S. D. Carson, A. FirTh and T. G. VINCENT (1986): Development plan for radiata pine breeding. Forest Research Institute, Rotorua, New Zealand.

Shelbourne, C. J. A. (1992): Genetic gains from different kinds of breeding population and seed or plant production populations. S. Afr. For. J. 160: 49-65. (also in Proc. IUFRO Conference of 1991 in Durban, South Africa) 
SNedDen, C. L. and S. D. VerRYN (2004): A comparative study of predicted gains for selection from a cloned breeding population and the implications for deployment. In: "Eucalyptus in a Changing World", edited by N. Borralho et al., 2004. Proc. IUFRO Conf., Aveiro, Portugal 11-15 October 2004.

VERRYN, S. D. and C. L. SNEDDEN (1998): G-assist version 3.0. A deterministic tool for genetic gains prediction. A user's manual. Water, Environment and Forestry Technology CSIR, Pretoria, South Africa.

\section{Appendix}

\section{Gain prediction equations}

For forwards selection in an OP breeding population (OPBP) for its reconstitution:

$$
\begin{aligned}
& \Delta \mathrm{G}_{\text {male }}=1 / 2 \mathrm{i}_{1} 1 / 4 \sigma_{\mathrm{A}}^{2} / \sigma_{\mathrm{fm}}+1 / 2 \mathrm{i}_{2} 3 /{ }_{4} \sigma_{\mathrm{A}}^{2} / \sigma_{\mathrm{w}} \\
& \text { Equation } 2 \\
& \Delta \mathrm{G}_{\text {female }}=1 / 2 \mathrm{i}_{3} 1 /{ }_{4} \sigma_{\mathrm{A}}^{2} / \sigma_{\text {fm }}+1 / 2 \mathrm{i}_{4} 3 /{ }_{4} \sigma_{\mathrm{A}}^{2} / \sigma_{\mathrm{w}}
\end{aligned}
$$

where: $\Delta \mathrm{G}_{\text {male }}$ and $\Delta \mathrm{G}_{\text {female }}$ are gains from selection of male and female parents;

$i_{1}$ and $i_{3}=$ selection intensity among families for males and females respectively; $i_{2}$ and $i_{4}=$ selection intensities within families for male and female parents; variance of half-sib family means, $\sigma^{2}{ }_{\mathrm{fm}}=1 /{ }_{4} \sigma_{\mathrm{A}}^{2}+\sigma^{2}{ }_{\mathrm{w}} / \mathrm{n}$; variance within half-sib families, $\sigma^{2}{ }_{\mathrm{w}}=3 /{ }_{4} \sigma_{\mathrm{A}}^{2}+\sigma_{\mathrm{e}}^{2} ; \sigma_{\mathrm{e}}^{2}=$ environmental variance; $\mathrm{n}=$ number of trees per family.

In the Main breeding population scenarios simulated below, there has been no explicit among-family selection. Selective thinning (of potential pollen parents) is only on phenotype within seedling families and on clone means within families, at a ratio of $20 \%$, i.e., reduction of the number of clones of a family from 25 to 5 and reduction of the number of seedlings of a family from 150 to 30 .

If selected individuals of the OPBP were grafted into an isolated archive and seed collected from there, the selection intensity would be the same for male and female parents. The expected gains from this procedure would be the same as for selection among and within polycross families. The same equation as \#2 applies for a polycross breeding population, but selection intensity within and among families is the same for males and females, provided that the pollen mix includes the same individuals selected as female parents. So equation 2 simplifies to the following:

$$
\Delta \mathrm{G}=\mathrm{i}_{1} 1 /{ }_{4} \sigma_{\mathrm{A}}^{2} / \sigma_{\mathrm{fm}}+\mathrm{i}_{2}{ }^{3}{ }_{4} \sigma^{2}{ }_{\mathrm{A}} / \sigma_{\mathrm{w}}
$$

Equation 3

For forwards selection in a full-sib breeding population the predicted gain is:

$$
\Delta \mathrm{G}=\mathrm{i}_{1} 1 /{ }_{2} \sigma_{\mathrm{A}}^{2} / \sigma_{\mathrm{fm}}+\mathrm{i}_{2} 1 /{ }_{2} \sigma_{\mathrm{A}}^{2} / \sigma_{\mathrm{wf}}
$$

Equation 4

where variance of full-sib family means, $\sigma_{\text {fmf }}^{2}=1 /{ }_{2} \sigma_{A}^{2}+$ $\sigma^{2}{ }_{w f} / \mathrm{n}$; variance within full-sib families, $\sigma^{2}{ }_{\mathrm{wf}}=1 /{ }_{2} \sigma_{\mathrm{A}}^{2}+$ $\sigma^{2}{ }^{2}$.

If breeding populations are cloned by propagating a number of seedlings per family as juvenile clones, it has been assumed that the family-mean selection component of gain is unaffected, only the within-family component (although family means are unaffected by cloning, the variance of family means is slightly changed, but this has not been incorporated in previous publications and
G_ASSIST). The gain from selection in a cloned openpollinated breeding population is:

$$
\begin{aligned}
& \Delta \mathrm{G}_{\text {male }}=1 / 2 \mathrm{i}_{1} 1 /{ }_{4} \sigma_{\mathrm{A}}^{2} / \sigma_{\mathrm{fm}}+1 /{ }_{2} \mathrm{i}_{2}{ }^{3 / 4} \sigma_{4}^{2}{ }_{\mathrm{A}} / \sigma_{\mathrm{c}} \\
& \Delta \mathrm{G}_{\text {female }}=1 / 2 \mathrm{i}_{3} 1 /{ }_{4} \sigma_{\mathrm{A}}^{2} / \sigma_{\mathrm{fm}}+1 /{ }_{2} \mathrm{i}_{4}{ }_{3}{ }_{4} \sigma_{\mathrm{A}}^{2} / \sigma_{\mathrm{c}}
\end{aligned}
$$

Equation 5

where within-half-sib family variance of clone means, $\sigma^{2}{ }_{c}=3 /{ }_{4} \sigma_{\mathrm{A}}^{2}+\sigma_{\mathrm{e}}^{2} / \mathrm{r}$; where $\mathrm{r}=$ number of ramets per clone.

For a cloned polycross breeding population, the predicted gain is the same as for the cloned OPBP, but is simplified, as selection intensity is the same for male as female parents:

$$
\Delta \mathrm{G}=\mathrm{i}_{1} 1 /{ }_{4} \sigma_{\mathrm{A}}^{2} / \sigma_{\mathrm{fm}}+\mathrm{i}_{2}{ }^{3} /{ }_{4} \sigma_{\mathrm{A}}^{2} / \sigma_{\mathrm{c}}
$$

Equation 6

For a cloned full-sib breeding population:

$$
\Delta \mathrm{G}=\mathrm{i}_{1} 1 /{ }_{2} \sigma_{\mathrm{A}}^{2} / \sigma_{\mathrm{fm}}+\mathrm{i}_{2} 1 /{ }_{2} \sigma_{\mathrm{A}}^{2} / \sigma_{\mathrm{cf}}
$$

Equation 7

where variance of within-full-sib family clone means, $\sigma_{\text {cf }}^{2}=1 /{ }_{2} \sigma_{\mathrm{A}}^{2}+\sigma_{\mathrm{e}}^{2} / \mathrm{r}$ where $\mathrm{r}=$ number of ramets per clone.

Gains from clonal seed orchards of forwards-selected parents, are predicted in the same way as for the respective breeding populations but in all cases the selection intensity is the same for male and female parents. Selection for orchards will involve intensive family selection, in contrast to the breeding populations. Gain from forwards-selected seedling parents, propagated in a clonal seed orchard is therefore:

$$
\begin{aligned}
\Delta \mathrm{G}= & \mathrm{i}_{1} 1 /{ }_{4} \sigma_{\mathrm{A}}^{2} / \sigma_{\mathrm{fm}}+\mathrm{i}_{2} 3 / 4 \sigma^{2}{ }_{\mathrm{A}} / \sigma_{\mathrm{w}} \text { for half-sib } \\
& \text { families, OP or polycross BPs } \\
\Delta \mathrm{G}= & \mathrm{i}_{1} 1 / \sigma_{2} \sigma_{\mathrm{A}}^{2} / \sigma_{\mathrm{fmf}}+\mathrm{i}_{2} 1 /{ }_{2} \sigma_{\mathrm{A}}^{2} / \sigma_{\mathrm{wf}} \\
& \text { for full-sib BPs }
\end{aligned}
$$

Equation 8

Equation 9

Gain for a clonal orchard from forwards selection in cloned half-sib and full-sib breeding populations is:

$$
\begin{aligned}
\Delta \mathrm{G}= & \mathrm{i}_{1} 1 /{ }_{4} \sigma_{\mathrm{A}}^{2} / \sigma_{\mathrm{fm}}+\mathrm{i}_{2}{ }^{3} /{ }_{4} \sigma_{\mathrm{A}}^{2} / \sigma_{\mathrm{c}} \\
& \text { for OP and polycross BPs } \\
\Delta \mathrm{G}= & \mathrm{i}_{1} 1 /{ }_{2} \sigma_{\mathrm{A}}^{2} / \sigma_{\mathrm{fmf}}+\mathrm{i}_{2} 1 /{ }_{2} \sigma_{\mathrm{A}}^{2} / \sigma_{\mathrm{cf}} \\
& \text { for full-sib BPs }
\end{aligned}
$$

Equation 10

Equation 11

Most seed orchards of radiata pine have been established after a further cycle of progeny testing of forwards selections. Gain from a backwards-selected orchard, resulting from forwards selections in seedling full-sib families, followed by progeny testing by openpollinated or polycross families, and then backwards selection is:

$$
\begin{aligned}
\Delta \mathrm{G}= & \mathrm{i}_{1} 1 /{ }_{2} \sigma_{\mathrm{A}}^{2} / \sigma_{\mathrm{fmf}}+\mathrm{i}_{2} 1 /{ }_{2} \sigma_{\mathrm{A}}^{2} / \sigma_{\mathrm{wf}} \\
& +2 \mathrm{i}_{3} 1 /{ }_{4} \sigma_{\mathrm{A}}^{2} / \sigma_{\mathrm{fm}}
\end{aligned}
$$

Equation 12

(note that gain from backwards selection is multiplied by 2 , as both male and female orchard parents are reselected on OP or polycross family means).

Gain from backwards selection, only, of the original OP breeding population parents (called "contemporaneous" backwards selection) is:

$$
\Delta \mathrm{G}=2 \mathrm{i}_{3} 1 /{ }_{4} \sigma_{\mathrm{A}}^{2} / \sigma_{\mathrm{fm}}
$$

Equation 13 